\title{
Review Article \\ Role of Erythropoietin and Other Growth Factors in Ex Vivo Erythropoiesis
}

\author{
Vimal Kishor Singh,, Abhishek Saini, ${ }^{1}$ and Ramesh Chandra ${ }^{2}$ \\ ${ }^{1}$ Stem Cell Research Laboratory, Department of Biotechnology, Delhi Technological University, Shahbad Daulatpur, \\ Bawana Road, Delhi 110042, India \\ ${ }^{2}$ Dr. B. R. Ambedkar Center for Biomedical Research, University of Delhi, Delhi 110007, India
}

Correspondence should be addressed to Vimal Kishor Singh; vim_kissor@yahoo.co.in

Received 28 April 2014; Accepted 9 September 2014; Published 2 October 2014

Academic Editor: Thomas Ichim

Copyright (C) 2014 Vimal Kishor Singh et al. This is an open access article distributed under the Creative Commons Attribution License, which permits unrestricted use, distribution, and reproduction in any medium, provided the original work is properly cited.

Erythropoiesis is a vital process governed through various factors. There is extreme unavailability of suitable donor due to rare phenotypic blood groups and other related complications like hemoglobinopathies, polytransfusion patients, and polyimmunization. Looking at the worldwide scarcity of blood, especially in low income countries and the battlefield, mimicking erythropoiesis using ex vivo methods can provide an efficient answer to various problems associated with present donor derived blood supply system. Fortunately, there are many ex vivo erythropoiesis methodologies being developed by various research groups using stem cells as the major source material for large scale blood production. Most of these ex vivo protocols use a cocktail of similar growth factors under overlapping growth conditions. Erythropoietin (EPO) is a key regulator in most ex vivo protocols along with other growth factors such as SCF, IL-3, IGF-1, and Flt-3. Now transfusable units of blood can be produced by using these protocols with their set of own limitations. The present paper focuses on the molecular mechanism and significance of various growth factors in these protocols that shall remain helpful for large scale production.

\section{Introduction}

According to a report by the World Health Organization (WHO), blood donation rate in high-income countries is 39.2 donations per 1000 population, whereas it is just 12.6 donations in middle-income and 4.0 donations in low-income countries out of which more than $50 \%$ of blood is being supplied by either family/replacement or paid donors. In contrast, just $34 \%$ of low- and middle-income countries have a provision of a national haemovigilance system which monitors and improves the safety of the transfusion process indicating that in such countries safe blood availability is a major concern [1]. To overcome the shortage of blood, ex vivo production of mature human red blood cells (RBCs) from stem cells of diverse origins has been demonstrated by various research groups [2]. While differing in initial material and methodology used by different research groups, they all converse at a single point in using EPO as a key regulator in the ex vivo RBC generation measures. In general, all the methods described so far mimic the marrow microenvironment through the application of cytokines and/or coculture on stromal cells, coupled with substantial amplification of stem cells with $100 \%$ terminal differentiation into fully mature, functional RBCs [2]. Neildez-Nguyen et al., 2002, in their studies demonstrated a method to amplify/expand hematopoietic stem cells (HSCs) from cord blood in a serum free culture medium. Human nucleated erythroid cells produced by this method when injected into nonobese diabetic, severe combined immunodeficient (NOD/SCID) mice showed proliferation and terminal differentiated into mature enucleated red blood cells (RBCs) [3]. As per their findings, sequential supply of specific combinations of cytokines in a stepwise manner helped them to obtain large scale ex vivo differentiated enucleated RBCs. In first step Flt3-L, SCF, and TPO stimulated proliferation of HSCs, which was then followed by SCF, EPO, and IGF-1 aiding in the proliferation of erythroid 
progenitors and finally terminal erythroid differentiation was promoted by EPO and IGF-1. Later, Giarratana et al. 2005, described an ex vivo methodology for producing fully mature human RBCs from hematopoietic stem/progenitor cells by applying G-CSF, IL-3, SCF, and EPO [4]. In 2008, Baek et al. demonstrated a method in which they cultured CD34+cells in a serum free medium supplemented with two cytokine sets $\mathrm{SCF}+\mathrm{IL}-3+\mathrm{EPO}$ and SCF + IL-3+ EPO+ TPO+ Flt3 for one week, followed by coculture upon mesenchymal cells derived from cord blood for two weeks to generate an almost pure clinical grade [5]. The same group in 2009 reported up to $95 \%$ of enucleation of in vitro generated RBCs by the addition of Poloxamer 188 as an RBC survival enhancer. This enhancer increases the stability of the RBC membrane and decreases the fragility [6]. Therefore, it can be assumed that ex vivo erythropoiesis can be carried out utilizing various sources, namely, embryonic stem cells (ESCs), induced pluripotent stem cells (iPSCs), and hematopoietic stem cells (HSCs), from various sources, for example, embryo, bone marrow, peripheral blood, or umbilical cord blood. While ESCs are the most promising source but have ethical issues associated with them on the other hand, iPSCs and HSCs are next to ESCs but their isolation and maintenance increase the cost of overall ex vivo culturing process. Many groups have reported use of mononuclear cells directly enriched with specific growth factors to overcome this issue but a specific protocol is the need of the hour. Till date most suitable method in terms of yield available for ex vivo erythropoiesis is presented by Giarratana et al. in which they used CD34+ cells (from bone marrow, umbilical cord blood, and peripheral blood mobilized with G-CSF to isolate) to culture them in modified serum free media in the presence of SCF, IL-3, and erythropoietin [4]. Fujimi et al. 2008 demonstrated a method with $100 \%$ enucleated RBCs by employing SCF, Flt-3/Flk-2+ TPO in first phase followed by SCF, IL-3+ EPO in the second phase [7]. NE Timmins et al. in 2011 developed a robust method to obtain ultra-high-yield of erythrocytes, with the expansion process having the capability of producing over 500 units of erythrocytes per umbilical cord blood donation using fully defined culture medium with the help of bioreactor [8].

As described by different research groups, all the ex vivo expansion measure would revolve around systemic and orderly use of different growth factors at various phases of ex vivo culture. In order to develop an optimal culturing procedure, a detailed knowledge of the growth factors and their significance along with mode of action shall be understood. There have been a large number of publications available about the structure, function, and significance of various growth factors in the regular erythropoietic process.

We attempt to discuss the significance of these growth factors specifically involved in ex vivo expansion methods for efficient measure in ex vivo erythropoietic expansion. Since erythropoietin has been developed as a central regulator of all the ex vivo RBCs production methods, more attention has been given to understand the various facets of its impact on the same.

If we compare ex vivo with in vivo erythropoiesis, it is regulated by several cytokines and factors.

\section{Erythropoiesis}

The process of erythropoiesis is initiated from the primitive pluripotent stem cells, giving rise to mature erythrocyte, which involves various regulatory factors inducing their commitment and further maturation of the cells involved in the red cell lineage. The major growth factors regulating in vivo erythropoiesis are granulocyte colony-stimulating factor (G-CSF), granulocyte macrophage colony-stimulating factor (GM-CSF), interleukin- (IL-) 3, stem cell factor (SCF), IL-1, IL-6, IL-4, IL-9, IL-11, insulin growth factor-1 (IGF1 ), and erythropoietin (EPO) $[9,10]$. Erythropoietin plays a pivotal role during later stages of erythroid maturation (Table 1). It acts primarily on colony forming unit erythroid (CFU-E) inducing the proliferation and maturation through the stages of proerythroblast followed by reticulocytes and finally mature erythrocytes [11]. CFU-E remains the primary target cell in the bone marrow for EPO, but it acts synergistically with other growth factors, namely, SCF, GMCSF, IL-3, IL-4, IL-9, and IGF-1, in order to regulate the maturation and proliferation starting from the stage of the burst-forming unit erythroid (BFU-E) followed by CFU-E to the proerythroblast stage of erythroid cell development $[2,12]$. SCF, IL-1, IL-3, IL-6, and IL-11 stimulate pluripotent stem cell to differentiate into the CFU granulocyte, erythroid, monocyte, megakaryocyte (GEMM), and the myeloid stem cell. The CFU-GEMM then differentiates into the specific CFU for erythroid, granulocytes, monocytes, macrophages, eosinophils, and megakaryocytes cell precursors in the presence of GM-CSF and IL3 [13]. These precursors finally differentiate into specific cell types.

In order to utilize/exploit these growth factors to copy or mimic nature in terms of generation of clinical grade red blood cells, we need to understand their role and how these growth factors are regulated in vivo. This review briefly describes the ex vivo expansion of erythrocytes followed by historical development information about erythropoietin and other growth factors. It then describes their role in erythropoiesis followed by our current understating of their use in ex vivo erythropoiesis and key challenges. Finally, it discusses the use of these growth factors in the production of clinical grade red blood cells.

\section{Ex Vivo Expansion of Erythrocytes: An Overview}

It is well understood that there is no substitute available for red blood cells, but its natural process of production can be mimicked to generate clinical grade RBCs. Many groups have shown to produce RBCs utilizing various sources of stem cells and different approaches in terms of media composition, growth factors, and so forth. This process of production of RBCs outside the living organism by providing the required microenvironment is termed as ex vivo erythropoiesis. The whole process can be divided into three main steps as follows:

(1) isolation of mononuclear or CD34+ population of hematopoietic stem cells; 
TABLE 1: Various growth factors and their functional implications in erythropoiesis.

\begin{tabular}{|c|c|c|c|c|c|}
\hline Sr. Number & Growth factor & Protein size & Target cells & Target receptor & Functions \\
\hline 1 & Erythropoietin & $21.0 \mathrm{kDa}$ & CFU-E & EPOR & $\begin{array}{l}\text { Differentiation and } \\
\text { proliferation of } \\
\text { erythroid }\end{array}$ \\
\hline 2 & $\begin{array}{l}\text { Granulocyte } \\
\text { macrophage } \\
\text { colony-stimulating } \\
\text { factor }\end{array}$ & $14.6 \mathrm{kDa}$ & $\begin{array}{l}\text { HPP-CFC, CFU-GEMM, } \\
\text { CFU-GM, CFU-Eo, CFU-Baso, } \\
\text { CFU-Mk, BFU-E, CFU-M, } \\
\text { CFU-G, dendritic cells }\end{array}$ & CD116 & $\begin{array}{l}\text { White blood cell } \\
\text { growth factor }\end{array}$ \\
\hline 3 & Interleukin-3 & $17.2 \mathrm{kDa}$ & $\begin{array}{l}\text { CFU-GEMM, HPP-CFC, } \\
\text { CFU-GM, CFU-Eo, CFU-Baso, } \\
\text { BFU-E, CFU-Mk }\end{array}$ & $\begin{array}{l}\text { CD123/IL3RA, } \\
\text { CD131/IL3RB }\end{array}$ & $\begin{array}{l}\text { Differentiation and } \\
\text { proliferation of } \\
\text { myeloid progenitor } \\
\text { cells }\end{array}$ \\
\hline 4 & Interleukin-6 & $20.9 \mathrm{kDa}$ & HPP-CFC, CFU-GM, BFU-E & $\begin{array}{l}\text { CD126/IL6RA, } \\
\text { CD130/IR6RB }\end{array}$ & Differentiation \\
\hline 5 & Stem cell factor & $42.0 \mathrm{kDa}$ & $\begin{array}{l}\text { HPP-CFC, CFU-GEMM, } \\
\text { CFU-GM, CFU-Baso, BFU-E }\end{array}$ & CD117 & $\begin{array}{l}\text { Regulates HSCs in the } \\
\text { bone marrow }\end{array}$ \\
\hline 6 & $\begin{array}{l}\text { Granulocyte } \\
\text { colony-stimulating } \\
\text { factor }\end{array}$ & $18.8 \mathrm{kDa}$ & $\begin{array}{l}\text { HPP-CFC, CFU-GEMM, } \\
\text { CFU-GM, CFU-G }\end{array}$ & CD114 & $\begin{array}{l}\text { Inducer of HSCs } \\
\text { mobilization from the } \\
\text { bone marrow into the } \\
\text { bloodstream }\end{array}$ \\
\hline 7 & $\begin{array}{l}\text { Insulin growth } \\
\text { factor }\end{array}$ & $7.6 \mathrm{kDa}$ & Endothelial progenitor cells & IGF1R & $\begin{array}{l}\text { Inhibits apoptosis in } \\
\text { hematopoietic } \\
\text { progenitor cells }\end{array}$ \\
\hline
\end{tabular}

(2) expansion of HSCs and differentiation into erythroid lineage;

(3) enucleation of reticulocytes to give rise to mature RBCs.

First and foremost, question arising is what should be the source of HSCs. To answer this, various groups have used different sources like umbilical cord blood, peripheral blood, bone marrow extracts, and induced pluripotent stem cells. But out of these the most commonly used source is umbilical cord blood, which has an advantage over other sources that to a greater extend human leukocyte antigen (HLA) mismatching is tolerated between donor and recipient and UCBs have been shown to expand more as compared to other sources.

Various research groups who have reported production of RBCs concluded that erythropoietin (EPO) the regulator of erythroid lineage is not sufficient for massive amplification of HSCs $[14,15]$. Therefore, different combinations of cytokines have been used by different research groups out of which SCF, IL-3, Flt-3, and TPO have been used most commonly for the expansion of HSCs [16-18].

For differentiation of erythroid lineages, many groups have used SCF, IL-3, and EPO with some exceptions who have added VEGF or TPO or IGF. Some groups have used coculture techniques and some have added animal or human sera for better growth, whereas Fujimi et al., 2008, have utilized them both. They later added Poloxamer 188 to increase the enucleation efficiency. NE Timmins demonstrated first RBC culture in large scale bioreactor [7]. All these findings converge at a single point that erythropoietin is the regulator of erythropoiesis which in the presence of other growth factors governs the process.

\section{Growth Factors Involved in Erythropoiesis}

The specific lineage of cells is promoted uniquely by chemical signals also known as cytokines and interleukins. Usually these substances are glycoproteins, which target specific cell stages. Their major function is to control replication, followed by clonal or lineage selection, and they are also responsible for maturation rate and growth inhibition of stem cells [19]. Now let us discuss each growth factor, first and foremost, erythropoietin. What makes it so important? And why? Erythropoietin (EPO) is a 193 amino acid glycoprotein with a molecular weight of $34 \mathrm{kDa}$. A functional EPO molecule comprises carbohydrate chains and sialic acid residues, which are indispensable for its production and secretion and fulfilling its biological function. Functionality of EPO depends on two disulfide bridges between cysteine residues. In case of adults, $80 \%$ of EPO is released by type I renal peritubular cells present in the renal cortical interstitium while remaining 20\% of EPO is produced in hepatic stellate cells present in liver. However, in the fetal stage its main source is only the liver. In human gene encoding EPO is located on chromosome 7 (loci 7q11-q22) and consists of 4 introns and 5 exons. Four key sequences of EPO gene are promoting, encoding, regulatory, and the one responsible for tissue specificity [20]. Besides the role of erythropoiesis EPO also inhibits apoptosis to decrease the rate of cell death in erythroid progenitor cells in the bone marrow and neural cells [21, 22]. Second, most important growth factor/cytokine is IL-3 which is supporting the proliferation of a broad range of hematopoietic stem cell types and involved in a variety of other cell activities such as cell growth, differentiation, and apoptosis followed by granulocyte macrophage colony-stimulating factor (GM$\mathrm{CSF}$ ) and granulocyte-colony-stimulating factor (G-CSF) 
which have established roles in hematopoiesis and have an established role as growth factors in clinical practice. G-CSF and GM-CSF regulate myeloid cell production, differentiation, and activation [23]. The addition of these growth factors is inevitable in ex vivo erythropoiesis as to attain desired differentiated product correct growth should be deployed and absence of other growth factors will ensure that the progenitor cells will differentiate only into the desired type of cell and make this process more efficient. Besides the media and growth factors, the bone marrow niche remains the major factor in ex vivo erythropoiesis, and this is also achievable by using 3D scaffolds. Let us now have a detailed discussion about each growth factor/cytokine.

Table 1 summarizes the functions of growth factors along with their protein size, on which receptor they bind, and what are their target cells and their functions.

\section{Erythropoietin: A Major Regulator of Ex Vivo RBC Production Measure}

Almost a century ago Carnot and Deflandre postulated a humoral factor and coined a term "hemopoietine," that regulates red blood cell production [24]. They carried out these intriguing experiments on rabbits, in which plasma from a donor rabbit was removed after a bleeding stimulus, and observed that when this plasma was injected into a normal recipient rabbit, it resulted in reticulocytosis. These findings were confirmed by several investigators; however, the most convincing confirmation of their work up to that time was reported by Hjort in 1936. Hjort reported that reticulocytosis produced normal recipients when erythropoietically active plasma from bled rabbits was injected into normal recipients in 18 sets of experiments [25].

So, it is evident that erythropoietin is a glycoprotein hormone produced mainly by peritubular capillary lining cells in the kidney and in the liver, which circulates in the plasma acting on target cells present in the bone marrow for the regulation of proliferation, differentiation, and maturation of red cells. Its amino acid sequence first mapped out in 1983 has a stimulating effect on bone marrow erythroid precursors. It has been demonstrated through structural studies of human EPO that it is a single polypeptide of $30.4 \mathrm{kD}$ with 193 amino acids residues which are folded into four $\alpha$-helices and contain two disulphide bridges between cysteines (6-161 and 29-33). EPO is also a structure homologue of growth hormone and other members of the hematopoietic class 1 cytokine super family [26].

The EPO receptor (EPOR) is expressed primarily on erythroid cells between the stages of CFU-E and the proerythroblast of erythroid cell development. The fewest number of EPO receptors is expressed on BFU-E which shows a weak response to EPO whereas CFU-E and the proerythroblasts show a higher number of EPOR. The number of EPOR per cell gradually decreases as the erythroid cell differentiates, and studies have revealed that the reticulocyte and mature erythrocyte lack EPO receptors. The EPO receptor is a protein ranging from 66 to $78 \mathrm{kD}$ in size and each EPO molecule binds two identical cell-surface receptors to activate progenitor cells. The EPO molecule consists of 4 helices, namely, $\alpha \mathrm{A}, \alpha \mathrm{B}, \alpha \mathrm{C}$, and $\alpha \mathrm{D}$, which display an up-up-downdown four-helical bundle topology where $\alpha \mathrm{A}$ and $\alpha \mathrm{D}$ helices are bound by a disulfide bond and $\alpha \mathrm{B}$ and $\alpha \mathrm{C}$ by a short loop [26]. EPO receptor exists as a preformed dimer which has been shown by protein fragment complementation assays and crystallographic studies. It has also been demonstrated that one molecule of EPO activates EPO receptors (EPOR) by dimerization of two EPO receptors and changes the conformation of the EPO receptor, which is necessary for Janus kinase- (JAK-) 2 activation by self-dimerization.

During erythropoiesis in vertebrates, EPO acts by binding to its receptor (EPOR) which is present on the surface of early erythroid progenitor cells and promotes cell survival, proliferation, and differentiation in the erythroid lineage $[27,28]$. But the expression of EPOR is upregulated during erythroid differentiation up to tenfold or more on the erythroid progenitor cells at the CFU-E stage where EPO signalling is required as protection against apoptosis. When EPO binds to erythroid progenitor cells, it upregulates its own receptor expression, which in turn increases EPO response along with the expression of erythroid-specific transcription factors and other erythroid-specific genes [29]. It has been observed that, during late erythropoiesis, expression of EPOR is downregulated and also EPO is not required anymore for cell survival [30]. Later the erythroid precursors give rise to reticulocytes by enucleation, and these reticulocytes continue to synthesize hemoglobin and then enter into the circulating blood to mature into erythrocytes. By the studying EPO activity in hematopoietic tissue, it has been observed that productive EPO signalling depends mainly on two factors: the EPOR expression level on the cell-surface and the local EPO concentration.

Besides expressing on hematopoietic cells EPOR is also expressed by certain other tissues like endothelial, muscle, neural, cardiovascular, and renal tissues [31]. The role of EPO in survival of cells, proliferation, and differentiation of the colony forming unit-erythrocyte indicates that it has some role to play in nonhematopoietic cells. EPO also has been shown to have cytoprotective or proliferative activity in nonhematopoietic tissues [32]; hence, in addition to increased red blood cell production, increased cell survival, and/or progenitor cell proliferation, it may have some contribution to EPO activity which helps in improving oxygen delivery through a direct effect on nonhematopoietic tissue as well. In another study, patients with chronic heart failure when treated with EPO show increase in cardiac systolic function. Other beneficial effects of EPO appear to be related to the proangiogenic properties on endothelial cells, which could be useful in the treatment of ischemic heart disease. Such kind of findings indicates that EPO in addition to anemia correction could provide potential therapeutic benefits in the management of cardiovascular diseases [33].

The ability of cells to form hemoglobinized erythroid colonies after adding EPO to bone marrow or spleen cells in clonal assays helps in identifying target cells for it. The most primitive erythroid progenitor is the burst-forming unit erythroid (BFU-E) and has a low sensitivity for EPO; therefore, it requires additional factors like stem cell factor (SCF), for survival and proliferation. The more committed 
erythroid colony-forming unit (CFU-E) on the other hand has comparatively limited proliferative potential compared to its precursor, the BFU-E, but is highly sensitive to EPO [34].

Interestingly, while $\mathrm{EPO}$ values are closely tied to the rate of red cell production, studies in knockout mice lacking EPO show that it is not required for development of BFU-E, the earliest committed red cell progenitors (that express only a small number of EPOR on their cell surface). As such, the EPO does not recruit cells to the erythroid lineage nor does it specify cell fate. Rather, EPO exerts its dynamic control over red cell formation by supporting the growth, survival, and differentiation of the progeny of erythroid committed progenitor cells, with the highest amounts of EPOR being found on late progenitor cells such as CFU-E.

Once EPO has bound and activated EPOR, a cascade of events is set in motion, including activation of the dimerized receptor [35] and signal transduction through JAK2, Stat5, MAP kinase protein kinase, PI3 kinase, and protein kinase C [36]. The actions of EPO include promotion of the survival of sensitive progenitors through prevention of apoptotic processes, stimulation of proliferation [37], and differentiation into large numbers of hemoglobinized cells. To maintain homeostasis and supply the necessary number of erythrocytes, the degree of proliferation required is quite remarkable and occurs in parallel with the acquisition of the features of the specialized functions of erythrocytes, accumulation of hemoglobin and disposal of the cell nucleus.

As discussed, the EPO does not act alone to stimulate erythropoiesis in the bone marrow. A host of other agents has been shown to affect EPO-driven erythropoiesis. The hierarchy of cell populations, leading to erythrocyte production, includes successively more specialized cell types. Among the primitive acting factors, SCF, the functional ligand for the $c$-kit cell-surface receptor, is one of the better understood factors. In mice anemic because of defects in either SCF or $c$-kit, administration of exogenous EPO still increases hemoglobin concentration [38], although to a modest degree. This result would suggest that the few CFU-E that survive functional SCF deficiency in vivo can still respond normally to exogenous EPO, though their numbers are reduced by limitations imposed on the cellular pathway at more primitive levels. The interaction of SCF and EPO, which is of obvious significance in these earlier populations, has been elegantly examined at the molecular level and shown to result from a subtle interplay of survival, proliferation, and differentiation signals [39].

EPO can also be used to increase hemoglobin, hematocrit values and reduce the requirement of RBC transfusions in ICU patients [40]. Studies in mice suggest that hematopoietic growth factors such as macrophage colony-stimulating factor (M-CSF) and granulocyte colony-stimulating factor (G-CSF) can cause tumor growth by promoting angiogenesis [41, 42], which supplies blood to solid tumors $[43,44]$. To test the effect of EPO in vivo, Okazaki et al. inoculated Lewis lung carcinoma cells (LLCs) into mice subcutaneously on day 0 and injected EPO or PBS into the mice once a week starting at day 1 and observed that erythropoietin significantly accelerated tumor growth. To test whether it was a direct effect of EPO on LLCs, an in vitro experiment was performed to examine the response of LLCs to EPO and it was found that EPO did not increase LLC proliferation. To avoid any high-growing background due to some growth factors present in the fetal calf serum (FCS), the response of LLCs to EPO under lowFCS culture medium condition was also examined and again EPO did not increase LLC proliferation under. So it can be said that the effect of EPO on LLC tumor growth seems to be indirect [45].

\section{GM-CSF}

Granulocyte macrophage colony-stimulating factor (GMCSF) is a member of the hematopoietic cytokine family and a $14.6 \mathrm{kDa}$ monomeric protein of 127 amino acids with two glycosylation sites. Its function is to stimulate the proliferation of granulocyte and/or macrophage progenitor cells, to influence differentiation, induce maturation, and stimulate the functional activity of mature hematopoietic cells [46, 47]. The other name of granulocyte macrophage colonystimulating factor receptor is CD116 (cluster of differentiation 116), to which granulocyte macrophage colony-stimulating factor binds and this receptor is not expressed on any erythroid or megakaryocytic lineage cells but on myeloblasts and mature neutrophils [46]. The granulocyte macrophage colony-stimulating factor receptor or CD116 occurs in the form of a heterodimer which is composed of at least two different subunits: an $\alpha$ chain and a $\beta$ chain. The binding site for granulocyte macrophage colony-stimulating factor is present on the $\alpha$ subunit [48], whereas the $\beta$ chain has a role in signal transduction and finally association of the $\alpha$ and $\beta$ subunits activates the receptor [49].

\section{IL-3 (Interleukin-3)}

Interleukin-3 originally was discovered by Ihle et al. in mice. In their studies, a $\mathrm{T}$ cell derived factor was responsible for inducing the synthesis of $20-\alpha$-hydroxysteroid dehydrogenase in hematopoietic cells and termed it as interleukin-3 [50, 51]. Interleukin gene encodes 152 -amino acid long sequence, making a $17 \mathrm{kDa}$ potent growth promoting cytokine. To determine its function, wide studies have been done like treating different states of bone marrow failure and mobilizing or expanding hematopoietic progenitor cells for transplantation and last but not easy to support engraftment after bone marrow transplantation [52].

\section{M-CSF}

M-CSF is a cytokine, its functional form of the protein is found extracellularly in disulfide-linked homodimer form, and it is produced by proteolytic cleavage of membranebound precursors [53]. It is one of the hematopoietic growth factors that has a major role in the proliferation, differentiation, and survival of monocytes, macrophages, and bone marrow progenitor cells [54]. M-CSF has several different ways to affect macrophages and monocytes, which includes stimulating increased phagocytic and chemotactic activity and increased tumor cell cytotoxicity [55]. 


\section{G-CSF}

Granulocyte colony-stimulating factor (G-CSF) was first reported and isolated from mouse in Walter and Eliza Hall Institute, Australia, in 1983 [56], and later in 1986 the human form was cloned by research groups from Japan and the USA/Germany $[57,58]$. Granulocyte colony-stimulating factor (G-CSF or GCSF), also called colony-stimulating factor 3 (CSF-3), is a glycoprotein whose major function is to stimulate the bone marrow to produce granulocytes and stem cells and release them into the bloodstream. Therefore, it can be said that, functionally, it is a cytokine and hormone, a type of colony-stimulating factor, which is produced by a number of different tissues. Besides this, it is also known to stimulate the survival, proliferation, differentiation, and function of both neutrophil precursors and mature neutrophils.

\section{Clinical Use and Limitations of Hematopoietic Growth Factors}

Erythropoietin (EPO) is often used in cancer treatment. But recent studies have shown that EPO can act on nonhematopoietic organs including solid tumors. The effect of EPO on the survival rate of cancer patients seems to be variable, as it has been observed that EPO decreases the survival of cancer patients with cancer in head and neck and metastatic breast, whereas in case of patients with small cell lung cancer erythropoiesis-stimulating agents (ESAs), which include EPO, it does not reduce the survival. In a study on 2,500 cases, which included most chronic renal failure cases, only two-thirds of patients were found to be able to predevelop hypertension and seizures as a side effect of rHuEPO. EPO has also been known to be associated with worsening of hypertension and hypertensive encephalopathy, which are less common scenario nowadays. There might be serious problems due to EPO antibodies such as pure red cell aplasia, but fortunately it is rare and clinicians are still using this drug in a new way to monitor closely for adverse side effects [59-63].

Recombinant GM-CSF has revolutionized the supportive care of cancer patients through significant contributions, like enhanced myeloid recovery after cytotoxic chemotherapy. In 1993 Dranoff et al. used GM-CSF as an important adjuvant in cancer vaccine trials, utilizing his observations that, when irradiated tumor cells expressing murine GM-CSF were used, they stimulated potent, long-lasting, and tumorspecific immunity [64]. Similarly Schmidt et al. demonstrated treatment of solid tumors (breast, renal cell carcinoma, malignant melanoma and prostate cancer) by utilizing GMCSF secreting transformed tumor cells as a potential cure [65].

However, no condition for the clinical use of IL-3 has been established so far, despite its theoretical advantages as an early-acting cytokine and in contrast to erythropoietin (EPO), G-CSF, or GM-CSF which has been approved for several clinical modalities.

Macrophage colony-stimulating factor (M-CSF), a growth factor stimulating the production of leukocytes including monocytes and neutrophils, has been clinically used as an agent for leukopenic patients after anticancer therapy. M-CSF improves a survival rate after bone marrow transplantation (BMT) through the reduction of mortality rate associated with BMT such as bleeding, engraftment failure, and GVHD. M-CSF has been known to accelerate platelet production when administered after anticancer therapy to thrombopenic patients with solid tumor. Granulocyte CSF (G-CSF) is a more powerful agent for various kinds of neutropenia such as neutropenia after anticancer therapy, neutropenia after BMT, aplastic anemia, chronic neutropenia of children, and myelodysplastic syndrome.

\section{Conclusion}

At present, there are few protocols available for ex vivo generation, refined enough to meet the demand of blood supply throughout the globe, especially for low-income countries and for the soldiers in the battlefield. There are reports of artificial blood being used for clinical trials. The key issues that are left unanswered are who will be responsible for the production and who will have distribution rights. Overall, it is a great vision of a scientist and is near to reality.

\section{Conflict of Interests}

The authors declare that there is no conflict of interests regarding the publication of this paper.

\section{Acknowledgments}

The authors thank Hon'able Chairman and Vice Chancellor of Delhi Technological University, Delhi, for support. Mr. Abhishek Saini, particularly, thanks the Department of Science and Technology (DST), India, for project assistance.

\section{References}

[1] Global Database on Blood Safety: Summary Report [Internet], World Health Organization, 2012, http://www.who.int/bloodsafety/global_database/GDBS_Summary_Report_2011.pdf.

[2] L. Douay, H. Lapillonne, and A. G. Turhan, "Stem cells-A source of adult red blood cells for transfusion purposes: present and future," Critical Care Clinics, vol. 25, no. 2, pp. 383-398, 2009.

[3] T. M. A. Neildez-Nguyen, H. Wajcman, M. C. Marden et al., "Human erythroid cells produced ex vivo at large scale differentiate into red blood cells in vivo," Nature Biotechnology, vol. 20, no. 5, pp. 467-472, 2002.

[4] M.-C. Giarratana, L. Kobari, H. Lapillonne et al., "Ex vivo generation of fully mature human red blood cells from hematopoietic stem cells," Nature Biotechnology, vol. 23, no. 1, pp. 69-74, 2005.

[5] E. J. Baek, H.-S. Kim, S. Kim, H. Jin, T.-Y. Choi, and H. O. Kim, "In vitro clinical-grade generation of red blood cells from human umbilical cord blood CD $34^{+}$cells," Transfusion, vol. 48, no. 10, pp. 2235-2245, 2008.

[6] E. J. Baek, H.-S. Kim, J.-H. Kim, N. J. Kim, and H. O. Kim, "Stroma-free mass production of clinical-grade red blood cells (RBCs) by using poloxamer 188 as an RBC survival enhancer," Transfusion, vol. 49, no. 11, pp. 2285-2295, 2009. 
[7] A. Fujimi, T. Matsunaga, M. Kobune et al., "Ex vivo large-scale generation of human red blood cells from cord blood CD $34^{+}$ cells by co-culturing with macrophages," International Journal of Hematology, vol. 87, no. 4, pp. 339-350, 2008.

[8] N. E. Timmins, S. Athanasas, M. Günther, P. Buntine, and L. K. Nielsen, "Ultra-high-yield manufacture of red blood cells from hematopoietic stem cells," Tissue Engineering C: Methods, vol. 17, no. 11, pp. 1131-1137, 2011.

[9] J. W. Adamson, The Story of Erythropoietin: ASH Anniversary Brochure, 50 Years in Hematology: Research That Revolutionized Patient Care, 2009.

[10] C. J. Gregory and A. C. Eaves, "Three stages of erythropoietic progenitor cell differentiation distinguished by a number of physical and biologic properties," Blood, vol. 51, no. 3, pp. 527537, 1978.

[11] R. S. Hillman and P. A. Henderson, "Control of marrow production by the level of iron supply," The Journal of Clinical Investigation, vol. 48, no. 3, pp. 454-460, 1969.

[12] X. Yu, J. J. Shacka, J. B. Eells et al., "Erythropoietin receptor signalling is required for normal brain development," Development, vol. 129, no. 2, pp. 505-516, 2002.

[13] B. R. Smith, "Regulation of hematopoiesis," Yale Journal of Biology and Medicine, vol. 63, no. 5, pp. 371-380, 1990.

[14] V. Munugalavadla and R. Kapur, "Role of c-Kit and erythropoietin receptor in erythropoiesis," Critical Reviews in Oncology/Hematology, vol. 54, no. 1, pp. 63-75, 2005.

[15] M. O. Arcasoy, K. Amin, S.-C. Chou, Z. A. Haroon, M. Varia, and J. A. Raleigh, "Erythropoietin and erythropoietin receptor expression in head and neck cancer: relationship to tumor hypoxia," Clinical Cancer Research, vol. 11, no. 1, pp. 20-27, 2005.

[16] H. Kawada, K. Ando, T. Tsuji et al., "Rapid ex vivo expansion of human umbilical cord hematopoietic progenitors using a novel culture system," Experimental Hematology, vol. 27, no. 5, pp. 904-915, 1999.

[17] X.-S. Jiang, C. Chai, Y. Zhang, R.-X. Zhuo, H.-Q. Mao, and K. W. Leong, "Surface-immobilization of adhesion peptides on substrate for ex vivo expansion of cryopreserved umbilical cord blood CD $34^{+}$cells," Biomaterials, vol. 27, no. 13, pp. 2723-2732, 2006.

[18] M. Drouet, J. Mathieu, N. Grenier, E. Multon, J.-J. Sotto, and F. Herodin, "The reduction of in vitro radiation-induced Fasrelated apoptosis in $\mathrm{CD} 34^{+}$progenitor cells by SCF, FLT-3 ligand, TPO, and IL-3 in combination resulted in $\mathrm{CD} 34^{+}$cell proliferation and differentiation," Stem Cells, vol. 17, no. 5, pp. 273-285, 1999.

[19] P. H. Lai, R. Everett, F. F. Wang, T. Arakawa, and E. Goldwasser, "Structural characterization of human erythropoietin," The Journal of Biological Chemistry, vol. 261, no. 7, pp. 3116-3121, 1986.

[20] M. L. Law, G. Y. Cai, F. K. Lin et al., "Chromosomal assignment of the human erythropoietin gene and its DNA polymorphism," Proceedings of the National Academy of Sciences of the United States of America, vol. 83, no. 18, pp. 6920-6924, 1986.

[21] A.-L. Sirén, M. Fratelli, M. Brines et al., "Erythropoietin prevents neuronal apoptosis after cerebral ischemia and metabolic stress," Proceedings of the National Academy of Sciences of the United States of America, vol. 98, no. 7, pp. 4044-4049, 2001.

[22] K. Motoyoshi, "Clinical application of hematopoietic growth factor (IL-3, G-CSF, GM-CSF, and EPO)," Nippon Rinsho, vol. 50, no. 8, pp. 1967-1972, 1992.
[23] C. A. Sieff, C. M. Niemeyer, D. G. Nathan et al., "Stimulation of human hematopoietic colony formation by recombinant gibbon multi-colony-stimulating factor or interleukin 3," Journal of Clinical Investigation, vol. 80, no. 3, pp. 818-823, 1987.

[24] P. Carnot and C. DeFlandre, "Surlactivite hemopoietique de serum au cours de la regeneration du sang," Comptes Rendus de l'Académie des Sciences, vol. 143, pp. 384-386, 1906.

[25] E. Hjort, "Reticulocyte increase after injection of anemic serum," Mag F Laegividensk, vol. 97, pp. 270-277, 1936.

[26] J. W. Fisher, "Erythropoietin: physiology and pharmacology update," Experimental Biology and Medicine, vol. 228, no. 1, pp. $1-14,2003$.

[27] H. Wu, X. Liu, R. Jaenisch, and H. F. Lodish, "Generation of committed erythroid BFU-E and CFU-E progenitors does not require erythropoietin or the erythropoietin receptor," Cell, vol. 83, no. 1, pp. 59-67, 1995.

[28] C.-S. Lin, S.-K. Lim, V. D’Agati, and F. Costantini, “Differential effects of an erythropoietin receptor gene disruption on primitive and definitive erytnropoiesis," Genes and Development, vol. 10, no. 2, pp. 154-164, 1996.

[29] T. Chiba, Y. Ikawa, and K. Todokoro, "GATA-1 transactivates erythropoietin receptor gene, and erythropoietin receptormediated signals enhance GATA-1 gene expression," Nucleic Acids Research, vol. 19, no. 14, pp. 3843-3848, 1991.

[30] H. M. Rogers, X. Yu, J. Wen, R. Smith, E. Fibach, and C. T. Noguchi, "Hypoxia alters progression of the erythroid program," Experimental Hematology, vol. 36, no. 1, pp. 17-27, 2008.

[31] M. Ogilvie, X. Yu, V. Nicolas-Metral et al., "Erythropoietin stimulates proliferation and interferes with differentiation of myoblasts," Journal of Biological Chemistry, vol. 275, no. 50, pp. 39754-39761, 2000.

[32] S. N. Constantinescu, T. Keren, M. Socolovsky, H.-S. Nam, Y. I. Henis, and H. F. Lodish, "Ligand-independent oligomerization of cell-surface erythropoietin receptor is mediated by the transmembrane domain," Proceedings of the National Academy of Sciences of the United States of America, vol. 98, no. 8, pp. 4379-4384, 2001.

[33] R. Raddino, D. Robba, G. Caretta et al., "Erythropoietin: a new perspective in cardiovascular therapy," Monaldi Archives for Chest Disease-Cardiac Series, vol. 70, no. 4, pp. 206-213, 2008.

[34] B. Wognum, "Erythropoietin mini review".

[35] M. O. Arcasoy, "The non-haematopoietic biological effects of erythropoietin," British Journal of Haematology, vol. 141, no. 1, pp. 14-31, 2008.

[36] C. Chen and A. J. Sytkowski, "Erythropoietin activates two distinct signaling pathways required for the initiation and the elongation of c-myc," Journal of Biological Chemistry, vol. 276, no. 42, pp. 38518-38526, 2001.

[37] S. B. Krantz, “Erythropoietin,” Blood, vol. 77, no. 3, pp. 419-434, 1991.

[38] P. N. Pharr, A. Hofbauer, R. E. Worthington, and G. D. Longmore, "Residual erythroid progenitors in w/w mice respond to erythropoietin in the absence of steel factor signals," International Journal of Hematology, vol. 72, no. 2, pp. 178-185, 2000.

[39] R. Kapur and L. Zhang, "A novel mechanism of cooperation between c-Kit and erythropoietin receptor. Stem cell factor induces the expression of Stat5 and erythropoietin receptor, resulting in efficient proliferation and survival by erythropoietin," The Journal of Biological Chemistry, vol. 276, no. 2, pp. 1099-1106, 2001. 
[40] J. R. Stubbs, "Alternatives to blood product transfusion in the critically ill: erythropoietin," Critical Care Medicine, vol. 34, no. 5, pp. S160-S169, 2006.

[41] T. Okazaki, S. Ebihara, H. Takahashi, M. Asada, A. Kanda, and H. Sasaki, "Macrophage colony-stimulating factor induces vascular endothelial growth factor production in skeletal muscle and promotes tumor angiogenesis," The Journal of Immunology, vol. 174, no. 12, pp. 7531-7538, 2005.

[42] T. Okazaki, S. Ebihara, M. Asada, A. Kanda, H. Sasaki, and M. Yamaya, "Granulocyte colony-stimulating factor promotes tumor angiogenesis via increasing circulating endothelial progenitor cells and $\mathrm{Grl}^{+} \mathrm{CD}_{11 b^{+}}$cells in cancer animal models," International Immunology, vol. 18, no. 1, pp. 1-9, 2006.

[43] J. Folkman, "Angiogenesis in cancer, vascular, rheumatoid and other disease," Nature Medicine, vol. 1, no. 1, pp. 27-31, 1995.

[44] N. Ferrara and R. S. Kerbel, "Angiogenesis as a therapeutic target," Nature, vol. 438, no. 7070, pp. 967-974, 2005.

[45] T. Okazaki, S. Ebihara, M. Asada, S. Yamanda, K. Niu, and H. Arai, "Erythropoietin promotes the growth of tumors lacking its receptor and decreases survival of tumor-bearing mice by enhancing angiogenesis," Neoplasia, vol. 10, no. 9, pp. 932-939, 2008.

[46] K. Inaba, M. Inaba, N. Romani et al., "Generation of large numbers of dendritic cells from mouse bone marrow cultures supplemented with granulocyte/macrophage colony-stimulating factor," Journal of Experimental Medicine, vol. 176, no. 6, pp. 1693-1702, 1992.

[47] D. Metcalf and N. A. Nicola, The Hematopoietic Colony Stimulating Factors, Cambridge University Press, New York, NY, USA, 1995.

[48] N. A. Nicola and D. Metcalf, "Binding of ${ }^{125}$ I-labeled granulocyte colony-stimulating factor to normal murine hemopoietic cells," Journal of Cellular Physiology, vol. 124, no. 2, pp. 313-321, 1985.

[49] B. J. McClure, T. R. Hercus, B. A. Cambareri et al., "Molecular assembly of the ternary granulocyte-macrophage colonystimulating factor receptor complex," Blood, vol. 101, no. 4, pp. 1308-1315, 2003.

[50] N. Geijsen, L. Koenderman, and P. J. Coffer, "Specificity in cytokine signal transduction: Lessons learned from the IL-3/IL5/GM-CSF receptor family," Cytokine \& Growth Factor Reviews, vol. 12, no. 1, pp. 19-25, 2001.

[51] J. N. Ihle, L. Pepersack, and L. Rebar, "Regulation of T cell differentiation: in vitro induction of $20 \alpha$-hydroxysteroid dehydrogenase in splenic lymphocytes from athymic mice by a unique lymphokine," Journal of Immunology, vol. 126, no. 6, pp. 2184-2189, 1981.

[52] J. N. Ihle, Y. Weinstein, J. Keller, L. Henderson, and E. Palaszynski, "Interleukin 3," Methods in Enzymology, vol. 116, pp. 540$552,1985$.

[53] Entrez Gene: CSF1 colony stimulating factor 1 (macrophage).

[54] E. R. Stanley, K. L. Berg, D. B. Einstein et al., "Biology and action of colony-stimulating factor-1," Molecular Reproduction and Development, vol. 46, no. 1, pp. 4-10, 1997.

[55] J. Nemunaitis, "Macrophage function activating cytokines: potential clinical application," Critical Reviews in Oncology/Hematology, vol. 14, no. 2, pp. 153-171, 1993.

[56] D. Metcalf, "The granulocyte-macrophage colony-stimulating factors," Science, vol. 229, no. 4708, pp. 16-22, 1985.

[57] S. Nagata, M. Tsuchiya, S. Asano et al., "Molecular cloning and expression of cDNA for human granulocyte colony-stimulating factor," Nature, vol. 319, no. 6052, pp. 415-418, 1986.
[58] L. M. Souza, T. C. Boone, J. Gabrilove et al., "Recombinant human granulocyte colony-stimulating factor: effects on normal and leukemic myeloid cells," Science, vol. 232, no. 4746, pp. 61-65, 1986.

[59] J. W. Adamson, "Erythropoietin: its role in the regulation of erythropoiesis and as a therapeutic in humans," Biotechnology, vol. 19, pp. 351-363, 1991.

[60] J. W. Adamson, "The relationship of erythropoietin and iron metabolism to red blood cell production in humans," Seminars in Oncology, vol. 21, no. 2, supplement 3, pp. 9-15, 1994.

[61] J. W. Adamson, "The erythropoietin-hematocrit relationship in normal and polycythemic man: implications of marrow regulation.", Blood, vol. 32, no. 4, pp. 597-609, 1968.

[62] A. P. Walden, J. D. Young, and E. Sharples, "Bench to bedside: a role for erythropoietin in sepsis," Critical Care, vol. 14, no. 4, article 227, 2010.

[63] E. Bieber, "Erythropoietin, the biology of erythropoiesis and epoetin alfa: an overview," Journal of Reproductive Medicine for the Obstetrician and Gynecologist, vol. 46, no. 5, pp. 521-530, 2001.

[64] G. Dranoff, E. Jaffee, A. Lazenby et al., "Vaccination with irradiated tumor cells engineered to secrete murine granulocytemacrophage colony-stimulating factor stimulates potent, specific, and long-lasting anti-tumor immunity," Proceedings of the National Academy of Sciences of the United States of America, vol. 90, no. 8, pp. 3539-3543, 1993.

[65] W. Schmidt, M. Buschle, W. Zauner et al., "Cell-free tumor antigen peptide-based cancer vaccines," Proceedings of the National Academy of Sciences of the United States of America, vol. 94, no. 7, pp. 3262-3267, 1997. 


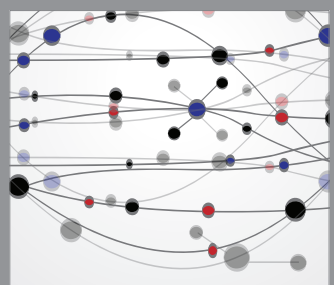

The Scientific World Journal
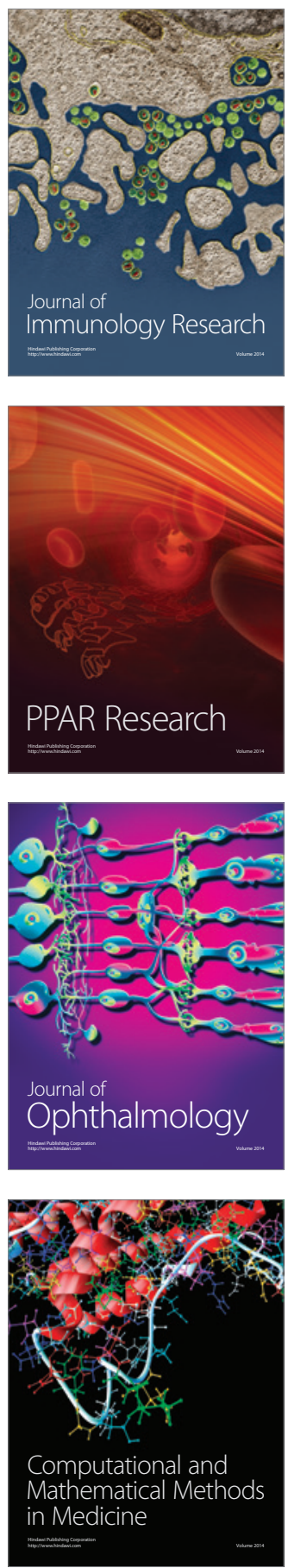

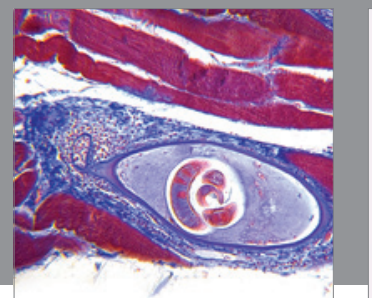

Gastroenterology

Research and Practice
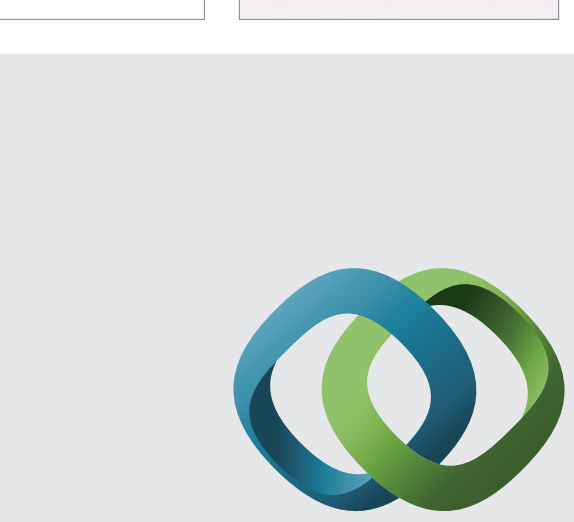

\section{Hindawi}

Submit your manuscripts at

http://www.hindawi.com
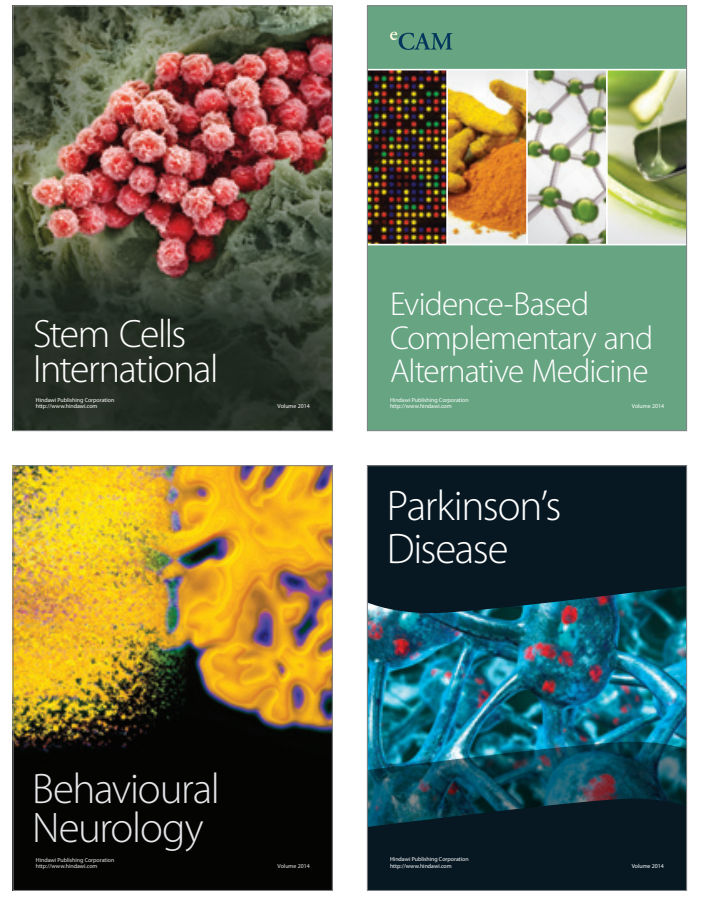
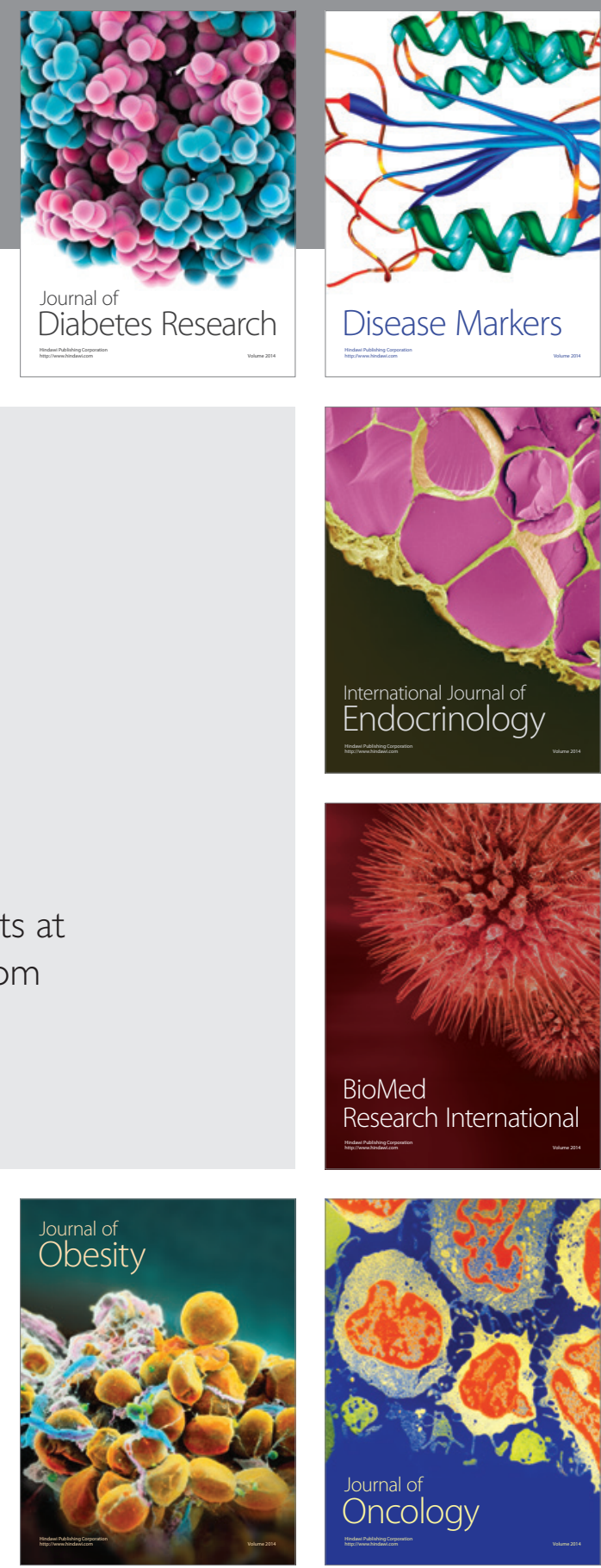

Disease Markers
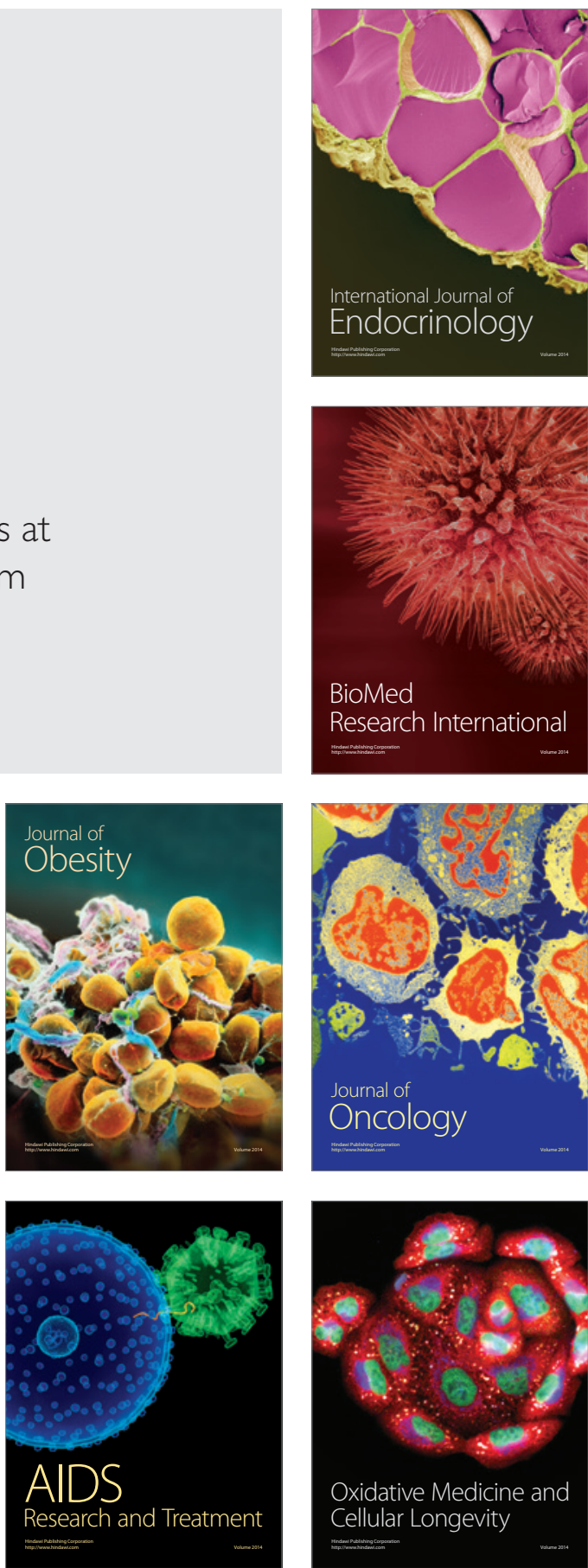